Andréa Cintra Lopes ${ }^{1}$

Cibele Carméllo Santos ${ }^{1}$

Kátia de Freitas Alvarenga ${ }^{1}$

Mariza Ribeiro Feniman ${ }^{1}$

Magali de Lourdes Caldana ${ }^{1}$

Ariádnes Nobrega de Oliveira ${ }^{2}$

Tatiane Martins Jorge ${ }^{2}$

José Roberto Magalhães Bastos²

\title{
Alterações auditivas em trabalhadores de indústrias madeireiras do interior de Rondônia
}

\author{
Hearing alterations in wood industry workers from the \\ countryside of Rondônia, Brazil
}

\begin{abstract}
${ }^{1}$ Departamento de Fonoaudiologia da Faculdade de Odontologia de Bauru/ Universidade de São Paulo (FOB/USP).

${ }^{2}$ Departamento de Odontopediatria, Ortodontia e Saúde Coletiva da FOB/USP
\end{abstract}

Contato:

Andréa Cintra Lopes

Professora Doutora do Departamento de Fonoaudiologia da FOB/USP

Al. Dr. Octavio Pinheiro Brizolla 9-75, 17012-901, Vila Universitária, Bauru/SP.

E-mail:

aclopes@usp.br

\section{Resumo}

O ruído ocupacional é considerado um risco físico bastante freqüente em quase todos os segmentos industriais e, desse modo, merece atenção especial por parte dos profissionais da saúde e segurança do trabalho. O presente estudo investigou a presença de queixas e alterações audiométricas em trabalhadores de indústrias madeireiras do interior de Rondônia. Participaram do estudo 16 trabalhadores de três indústrias, os quais foram submetidos a uma entrevista sobre a audição, bem como ao exame audiológico por meio da audiometria tonal liminar e da imitanciometria. Todos os participantes eram do gênero masculino, sendo que a maioria apresentava idade inferior a 25 anos e referiu não haver concluído o Ensino Fundamental. Queixas auditivas e uso de protetor auricular foram referidos pela metade da amostra. Os traçados audiométricos revelaram alteração na metade da amostra.

Palavras-chave: ruído, audição, audiometria, saúde do trabalhador, indústria da madeira.

\begin{abstract}
Occupational noise is considered a physical risk that is frequent in almost all industrial segments. That is why occupational safety and health professionals give it special attention. The present study investigated the presence of audiometric alterations in wood industry workers from the countryside of Rondônia, Brazil. Sixteen workers of three industries took part in the study. They were interviewed on their hearing capacities and went through audiologic examination by means of preliminary tonal audiometry and acustic impedance tests. All the participants were male, most of them under 25 years old. They reported not having finished elementary school. Half of the sample presented auditory complaints and mentioned use of hearing protectors. Audiometric tracings disclosed alterations in half of the sample.
\end{abstract}

Keywords: noise, hearing, audiometry, occupational health, wood industry. 


\section{Introdução}

O ruído ocupacional é considerado um risco físico bastante freqüente em quase todos os segmentos industriais (ALMEIDA et al., 2000) e, desse modo, merece atenção especial por parte dos profissionais da saúde e segurança do trabalho. Além de comprometer a audição, o ruído pode perturbar o descanso, o sono e a comunicação dos seres humanos (FIORINI, 2004), afetando diretamente a qualidade de vida. O ruído ocupacional pode, ainda, contribuir para os acidentes no local de trabalho, uma vez que prejudica a comunicação, a manutenção da atenção, da concentração e da memória, além de aumentar o estresse e a fadiga excessiva (FERREIRA JÚNIOR, 2000).

Por sua inegável importância, o ruído tem recebido exclusividade nas abordagens relacionadas à saúde auditiva dos trabalhadores (MELLO; WAISMANN, 2004) e tem sido alvo de muitas pesquisas. Vários estudos com trabalhadores expostos ao ruído ocupacional apontam para alta prevalência de perda auditiva induzida por ruído - PAIR (PORTO et al., 2004; RIOS; SILVA, 2005). No entanto, é valido salientar que, embora a PAIR tenha atingido proporções endêmicas no meio industrial, estudos científicos sobre a história natural nos trabalhadores são escassos, além de existir grande imprecisão na quantificação do nível de exposição individual ao ruído, observada nas indústrias brasileiras (GUERRA et al., 2005).

Dentre as indústrias brasileiras, as madeireiras têm tido destaque na região norte do país. De acordo com registros do Instituto Brasileiro de Meio Ambiente e dos Recursos Naturais Renováveis (Ibama) ${ }^{3}$ existem, aproximadamente, 3.360 indústrias madeireiras na região amazônica. É importante destacar que, em quase todos os processos do beneficiamento da madeira, o ruído está presente. A falta de manutenção e instalações adequadas, aliadas a um layout ineficiente, contribuem para o aumento do ruído nos ambientes das madeireiras. Além disso, o tipo de madeira também ocasiona maior ou menor nível de pressão sonora. O desconhecimento e a negligência em relação às práticas seguras são evidenciados nessas indústrias, onde se encontram níveis de ruído que variam de 90 a 120 dB. Em geral, os setores menos ruidosos são os de embalagem e de armazenagem. Ainda assim, muitas vezes, os operários, ao manusearem o produto acabado em forma de prancha, provocam ruído de impacto que pode atingir $95 \mathrm{~dB}$ (SEIXAS; BARBOSA; RUMMER, 2004).

Apesar de o setor da indústria madeireira provocar grande impacto negativo no ambiente e na saúde dos trabalhadores, a literatura é escassa ao relatar os efeitos do ruído na audição de funcionários desse tipo de indústria. Lucchini et al. (1991), em pesquisa realizada com 41 trabalhadores de madeireiras, verificaram que $45,9 \%$ da amostra apresentava perda auditiva na freqüência de $6 \mathrm{KHz}$.

Considerando a necessidade de se conhecer o perfil audiológico dos trabalhadores de indústrias madeireiras, este estudo investigou a presença de queixas auditivas e alterações audiométricas que possam estar associadas aos efeitos do ruído na audição de trabalhadores de indústrias madeireiras do interior de Rondônia, assim como o grau de conhecimento desses trabalhadores sobre o assunto.

\section{Metodologia}

Este estudo foi desenvolvido por alunos de graduação e pós-graduação em Fonoaudiologia e Saúde Coletiva da Faculdade de Odontologia de Bauru/Universidade de São Paulo (FOB/USP), durante a $10^{\mathrm{a}}$. Expedição de Extensão Universitária ao município de Monte Negro/RO. Obteve aprovação do Comitê de Ética em Pesquisa, protocolo $\mathrm{n}^{\circ} 89 / 2004$

\section{1ª etapa: Palestra sobre "Saúde Auditiva"}

Participaram 53 trabalhadores de 3 madeireiras. Foram esclarecidos temas sobre prevenção, detecção e reabilitação de perdas auditivas e atuação em equipes multidisciplinares. Também foram abordados aspectos relacionados à perda auditiva no trabalho (causas, fatores endógenos e exógenos, efeitos auditivos e não auditivos), orientações sobre o uso de Equipamento de Proteção Individual (EPI) e sua importância na prevenção de perdas auditivas induzidas pelo ruído.

\section{$2^{\text {a }}$ etapa: Avaliação audiológica}

Dos 53 participantes, foram excluídos aqueles que apresentavam quadros neurológicos e/ou malformação craniofacial (4 trabalhadores) ou faixa etária superior a 60 anos (11 trabalhadores). Dos 38 restantes, apenas 16 concluíram a avaliação audiológica, ou seja, 30,18\% dos trabalhadores que participaram da palestra.

A avaliação audiológica foi realizada com 14 horas de repouso auditivo. Após a entrevista especifica, os trabalhadores foram submetidos à avaliação, a partir dos seguintes exames:

- Audiometria tonal liminar: realizada em cabina acústica, utilizando-se o audiômetro modelo Midimate 622 com fone TDH 39; investigou-se o limiar auditivo nas freqüências entre 250, 500, 1000, 2000, 3000, 4000, 6000 e $8000 \mathrm{~Hz}$, por via aérea e nas freqüências de 500, 1000, 2000, 3000 
e $4000 \mathrm{~Hz}$ por via óssea quando essas freqüências encontravam-se abaixo de $20 \mathrm{~dB}$ na via aérea. Os resultados das audiometrias foram analisados de acordo com a classificação proposta por Fiorini (1994), definindo-se como: 'normal', os limiares iguais ou inferiores a $25 \mathrm{~dB}$; 'normal com entalhe', o rebaixamento em uma das freqüências de 3, 4 ou $6 \mathrm{KHz}$ com diferença de pelo menos $10 \mathrm{~dB}$ em relação à freqüência anterior ou posterior; 'traçado audiométrico sugestivo de PAIR', a configuração de PAIR mas ainda com limiares auditivos acima de $25 \mathrm{~dB}$ nas freqüências de 3, 4 ou $6 \mathrm{KHz}$. Além disso, considerou-se como 'Outros', os traçados que evidenciaram limiares maiores que $30 \mathrm{~dB}$ em alguma freqüência, que não corresponda ao sugestivo de PAIR.

- Imitânciometria: realizada fora da cabina acústica, utilizando-se o equipamento AZ 7; investigou-se a funcionalidade da orelha média.

\section{Resultados}

Os resultados da entrevista indicaram que todos os participantes eram do gênero masculino, com idades entre 16 e 47 anos (média de 26 anos), com 62,5\% dos participantes apresentando idade inferior a 25 anos.

Quanto à escolaridade, 56,25\% mencionaram não haver concluído o Ensino Fundamental, 31,25\% estavam cursando o Ensino Médio e 12,5\% haviam concluído o Ensino Fundamental.

Quanto à saúde, as doenças mais relatadas foram a 'caxumba' $(56,25 \%)$ e 'malária' (50\%). Dentre os que mencionaram haver contraído malária, $75 \%$ referiram que o quadro se repetiu por 10 vezes, enquanto os demais mencionaram 20 vezes; todos foram medicados com quinino. Hipertensão arterial e leishmaniose foram mencionadas por $12,5 \%$, nenhum participante mencionou 'fumar' e 56,25\% referiram 'ingerir bebidas alcoólicas' esporadicamente.

Queixas auditivas foram mencionadas por 50\% da amostra, destas queixas as mais freqüentes foram otalgia, citadas por $25 \%$ dos participantes, e zumbido, por $12,5 \%$ da amostra.

Quando indagados sobre o tempo de início da atividade profissional, 56,25\% referiram 'há menos de cinco anos', $25 \%$ entre 'cinco e dez anos' e 18,75\% ‘há mais de 10 anos'.

Em relação ao ambiente profissional, todos os participantes consideraram o local ruidoso, embora 50\% da amostra tenha informado que 'nunca se incomoda com o ruído', enquanto $25 \%$ que 'sempre se incomoda com o ruído'.

Quanto ao uso de EPI, 50\% dos operários referiram utilizá-los, dentre os quais foram mencionados o modelo 'concha' (75\%) e o modelo 'plug' (25\%). Dos que informaram usar EPI, 62,5\% mencionaram utilizar o equipamento durante oito horas por dia, ou seja, durante toda a jornada de trabalho, enquanto os demais o fazem por menor carga horária.

Com relação ao conhecimento dos participantes sobre perda auditiva no trabalho, 93,75\% dos participantes responderam que sabiam da relação causal entre ruído e perda auditiva e $81,25 \%$ responderam que existe cura para a PAIR.

Os resultados da audiomettria evidenciaram 50\% da amostra com resultados 'normal', enquanto 31,25\% foram classificadas em 'normal com entalhe', 13,5\% 'sugestivo de PAIR' e 6,25\% foram classificadas como 'outras alterações audiométricas'.

$\mathrm{Na}$ imitanciometria, todos os participantes (100\%) apresentaram curva timpanométrica do tipo A, bilateralmente, o que representou ausência de alterações na orelha média.

\section{Discussão}

A saúde do trabalhador é tema reconhecido e discutido por profissionais de diversas áreas de conhecimento, como médicos, psicólogos, fonoaudiólogos, assim como por equipes de gestão.

Com relação à presença de menores de 18 anos nas madeireiras, possivelmente possa ser atribuída à insuficiência de fiscalização, como citado por Pignati e Machado (2005). Vale ressaltar que nessa casuística havia trabalhadores com 16 anos de idade há mais de um ano nesse ambiente de trabalho.

No que se refere à saúde, constatou-se alta ocorrência de histórico de caxumba e malária entre os participantes, doenças que são freqüentes na região norte do país. É importante mencionar que a malária é uma doença muito comum na região investigada, principalmente para os indivíduos que freqüentam a mata. Essas doenças, além de serem tratadas com quinino, medicamento ototóxico, também são tratadas com ervas da região, as quais não se sabe se são ou não potencialmente tóxicas para o sistema auditivo. Estes dados sugerem a necessidade de um estudo para verificar possíveis contribuições do uso de medicamentos nos problemas auditivos de trabalhadores da região

Quanto ao ambiente profissional, todos os participantes consideraram o local ruidoso, embora 50\% tenham mencionado incomodar-se com o ruído do ambiente, informação esta que era esperada, uma vez que, de acordo com Ferreira Júnior (2000), os efeitos do ruído na audição ocorrem, aproximadamente, a partir de cinco anos de exposição.

Em visitas realizadas nas 3 madeireiras, observouse que as medidas coletivas para prevenção da PAIR são pouco difundidas. Mesmo sob essas circunstâncias, 
apenas 50\% dos participantes referiram utilizar o EPI, dado este preocupante quando observado os resultados da avaliação audiológica, indicando 44,75\% (31,25\% $+13,5 \%$ ) da amostra com alterações evidentes na audiometria, que pode ser justificado pela adoção insuficiente de medidas de proteção. Dos $50 \%$ dos participantes que informaram usar EPI, 62,5\% mencionaram utilizá-lo oito horas por dia, enquanto $37,5 \%$ o fazem por menor carga horária diária, resultados inferiores ao descrito por Zocoli e Silva (1995), em que o uso do EPI foi mencionado por $72,4 \%$ dos entrevistados. Estes dados podem indicar descaso da empresa ou desconhecimento das formas de prevenção da deficiência auditiva. Nota-se que o desenvolvimento de programas que visam promover a saúde auditiva de seus empregados ocorre nas empresas mais conscientes de suas responsabilidades trabalhistas (COLON et al., 2000). Diante desse quadro, coloca-se como determinante o desenvolvimento de programas de vigilância à saúde desses trabalhadores.

Quanto aos achados audiométricos, devem ser considerados relevantes para o acompanhamento audiológico periódico com o objetivo de evitar a progressão dos limiares audiométricos e a adoção de medidas de prevenção da perda auditiva, com ênfase em medidas de proteção coletiva e, complementarmente, com o uso de EPI. O número total de audiogramas alterados que sugerem deficiência auditiva envolvendo o ruído soma $44,75 \%$, o que indica uma proporção alarmante, visto que a deficiência auditiva de origem ocupacional pode ser prevenida. Deve-se ainda levar em conta o custo para diagnóstico e tratamento e os efeitos psicossociais, difíceis de serem mensurados.

\section{Referências}

ALMEIDA, S. I. C. et al. História natural da perda auditiva ocupacional provocada por ruído. Revista da Associação Médica Brasileira, São Paulo, v. 46, n. 2, p.143-158, jun. 2000.

COLON, J. C. et al. Conhecimento e conduta de empresários frente ao alto nível de ruído nos ambientes de trabalho. In: ENCONTRO INTERNACIONAL DE AUDIOLOGIA, 15., 2000, Bauru. Anais... Bauru: Hospital de Reabilitação de Anomalias Craniofaciais da Universidade de São Paulo, 2000. p. 54.

\section{COMITÊ NACIONAL DE RUÍDO E CONSERVAÇÃO}

AUDITIVA. Diretrizes básicas de um PCA (Programa de Conservação Auditiva): recomendações mínimas para a elaboração de um PCA. Arquivos Internacioanis de Otorrinolaringologia, São Paulo, v. 4, n. 2, 2000. Boletim n. 8. Disponível em: <http:// www.arquivosdeorl.org.br/conteudo/acervo_port. asp?id=125>. Acesso em: 12 abr. 2004.
Dentre as recomendações mínimas estipuladas pelo Comitê Nacional de Ruído e Conservação Auditiva (2000) para a elaboração de programas de conservação auditiva, encontram-se as medidas educativas e motivacionais. Tais medidas são consideradas importantes para estimular a prevenção auditiva nas indústrias, junto aos funcionários e proprietários.

Finalmente, cabe registrar a necessidade de maior investimento em estudos e pesquisas capazes de fornecer subsídios para repensar e criar estratégias viáveis de intervenção.

\section{Considerações finais}

A realização deste trabalho evidenciou:

- A existência de carências estruturais, no setor da indústria madeireira, relacionadas aos aspectos de prevenção e controle de ruídos;

- A necessidade de implantação de medidas de controle de ruído na fonte;

- A relevância da realização de acompanhamento audiológico periódico com a finalidade de prevenção de perda auditiva.

- A importância da iniciativa e do envolvimento da universidade junto aos trabalhadores e empresários das indústrias madeireiras do município de Monte Negro/RO como forma de contribuir para as transformações necessárias que devem determinar um ambiente seguro e saudável.

FERREIRA JÚNIOR, M. Perda auditiva induzida pelo ruído. In: FERREIRA JÚNIOR., M. (Ed.). Saúde no trabalho. São Paulo: Roca, 2000. p. 262-285.

FIORINI, A. C. Audição: impacto ambiental e ocupacional. In: FERREIRA, L. P.; BERFI-LOPES, D. M.; LIMONGI, S. C. O. (Org.). Tratado de fonoaudiologia. São Paulo: Roca, 2004. p. 631-642.

. Conservação auditiva: estudo sobre o monitoramento audiométrico em trabalhadores de uma indústria metalúrgica. 1994. 98 f. Dissertação (Mestrado em Distúrbios da Comunicação) - Pontifícia Universidade Católica de São Paulo, São Paulo, 1994.

GUERRA, M. R. et al. Prevalência da perda auditiva induzida por ruído em empresa metalúrgica. Revista de Saúde Pública, São Paulo, v. 39, n. 2, p. 238-244, abr. 2005.

LUCCHINI, R. et al. Effects on hearing in exposure to impulsive and high frequency noise. La Medicina del lavoro, Italy, v. 82, n. 6, p. 547-553, Nov./Dec. 1991. 
MELLO, A. P.; WAISMANN, W. Exposição ocupacional ao ruído e químicos industriais e seus efeitos no sistema auditivo: revisão da literatura. Arquivos Internacionais de Otorrinolaringologia, v. 8, n. 3, jul./set. 2004. Disponível em: <http://www.arquivosdeorl.org.br/ conteudo/acervo_port.asp?id=285 > . Acesso em: 23/03/07.

PIGNATI, W. A.; MACHADO, J. M. H. Riscos e agravos à saúde e à vida dos trabalhadores das indústrias madeireiras de Mato Grosso. Ciência \& Saúde Coletiva, Rio de Janeiro, v. 10, n. 4, p. 961-973, dez. 2005.

PORTO, M. A. A. et al. Avaliação da audição em freqüências ultra-altas em indivíduos expostos ao ruído ocupacional. Pró-Fono Revista de Atualização Cientifica, São Paulo, v. 16, n. 3, p. 237-250, 2004.

RIOS, A. L.; SILVA, G. A. Sleep quality in noise exposed Brazilian workers. Noise \& Health, England, v. 7, n. 29, p. 1-6, Oct./Nov. 2005.

SEIXAS, F.; BARBOSA, R. A.; RUMMER, R. Tecnologia protege saúde do operador. Revista da Madeira, Curitiba, v. 82, p. 68-73, 2004.

ZOCOLI, R.; SILVA, A. M. P. Perfil audiológico em indústrias madeireiras. Revista Brasileira de Otorrinolaringolologia, São Paulo, v. 61, n. 3, p 188-192, maio/jun. 1995 